\title{
Gestational Diabetes Mellitus and Its Associated Risk Factors in Pregnant Women at Selected Health Facilities in Kigali City, Rwanda
}

\author{
Jean Baptsite Niyibizi ${ }^{*}$, Florien Safari ${ }^{2}$, Jean Bosco Ahishakiye ${ }^{3}$, \\ Jean Bosco Habimana4, Herbert Mapira5, Ngule Chrispus Mutuku6 \\ ${ }^{1}$ Pan African University Institute of Sciences, Technology and Innovation, Nairobi, Kenya \\ ${ }^{2}$ Nyagatare Hospital, Nyagatare, Rwanda \\ ${ }^{3}$ Rwinkwavu Hospital, Kayonza, Rwanda \\ ${ }^{4}$ Gisenyi Hospital, Rubavu, Rwanda \\ ${ }^{5}$ College of Medicine and Health Sciences, University of Rwanda, Kigali, Rwanda \\ ${ }^{6}$ Center for Traditional Medicine and Drugs Research, Kenya Medical Research Institute, Nairobi, Kenya \\ Email: *niyibizi3@gmail.com
}

How to cite this paper: Niyibizi, J.B., Safari, F., Ahishakiye, J.B., Habimana, J.B., Mapira, H. and Mutuku, N.C. (2016) Gestational Diabetes Mellitus and Its Associated Risk Factors in Pregnant Women at Selected Health Facilities in Kigali City, Rwanda. Journal of Diabetes Mellitus, 6, 269-276. http://dx.doi.org/10.4236/jdm.2016.64028

Received: August 25, 2016

Accepted: October 31, 2016

Published: November 2, 2016

Copyright (c) 2016 by authors and Scientific Research Publishing Inc. This work is licensed under the Creative Commons Attribution International License (CC BY 4.0).

http://creativecommons.org/licenses/by/4.0/ (c) (†) Open Access

\section{Abstract}

Background: Gestational Diabetes Mellitus (GDM) is the most common complication of pregnancy that causes chronic hypertension, increased rate of cesarean delivery, fetal mortality and morbidity. Therefore, early diagnosis of GDM is vital to reduce maternal and fetal morbidity. Moreover, it can circumvent or procrastinate the onset of type 2 diabetes. Objectives: The main objective of this study was to determine the prevalence of GDM in pregnant women attending Kimironko, Kicukiro and Muhima Health Centres. The specific objectives were to determine the blood glucose during the second trimester in pregnant women aged between 21 and 45 years, to find out the frequencies of pregnant women presenting with GDM according to age and to assess some promising risk factors associated with GDM. Methods: A cross-sectional study was carried out at Kimironko, Kicukiro and Muhima Health centers using a sample size of 96 pregnant women. Blood glucose levels were measured using glucose oxidase method with a glucometer. Data were analyzed by using Microsoft Office Excel and SPSS version 20. Results: Out of 96 pregnant women who participated in the study, $8.3 \%$ were found to have GDM with the mean $\pm 2 \mathrm{SD}$ of $194.12 \pm 25.53 \mathrm{mg} / \mathrm{dl}$ of their blood glucose results (Mean \pm 2 SD: A 95\% level of confidence Intervals). The highest proportion of GDM was revealed in pregnant women aged between 26 - 30 years, representing a frequency of $5.2 \%$ whereas $2.1 \%$ of GDM was reflected in women aged between $21-25$ years. The lowest proportion of GDM fell in age group of 31 - 35 years contributing to $1 \%$ of the total GDM. There were no cases of GDM in pregnant women in the $36-40$ 
or 41 - 45 age groups. The mean \pm 2 SD of participant's age groups was $27.12 \pm 5.01$ years. In addition, while obesity did not show to be associated with GDM, age and family history were found to be risk factors of GDM. Conclusion: The findings of this study revealed that the prevalence of GDM was $8.3 \%$ and the most affected pregnant women were in the age group of 26 - 30 years.

\section{Keywords}

Gestational Diabetes Mellitus (GDM), Prevalence, Pregnancy, Age Group, Risk Factors

\section{Introduction}

GDM is a high blood sugar condition that some women acquire during pregnancy and it usually starts halfway through the pregnancy between the $24^{\text {th }}$ and $28^{\text {th }}$ week of pregnancy [1]. Placental hormones and increased fat deposits mediate insulin resistance during pregnancy thereby blocking insulin action to bind its receptors that is why this condition causes high level of glucose in pregnant women [2]. This hyperglycemia is first recognized during pregnancy in previously undiagnosed patients but it usually resolves after pregnancy [3]. It is a public health problem that currently affects a large part of the female population and has short- and long-term consequences for the fetus and the mother [1]. Approximately $7 \%$ of all pregnancies are complicated by GDM, resulting in more than 200,000 worldwide cases annually and the prevalence may range from $1 \%$ to $14 \%$ of all pregnancies depending on the population studied and the diagnostic tests employed [4].

Approximately between 3 and 10 percent of expectant mothers develop this condition (GDM), making it one of the most common health problems of pregnancy [5]. It is a major cause of prenatal morbidity and mortality, as well as maternal morbidity [1]. It is therefore imperative that these mothers are diagnosed during pregnancy and that they have a regular postpartum follow-up for identification and treatment of any complications [6]. More important is that women with GDM have an increased risk of developing diabetes after pregnancy when compared to the general population, with a conversion rate of up to $3 \%$ per year [7]. In the majority of cases, the response to Oral Glucose Tolerance Test (OGTT) reverts to normal after pregnancy, but about $50 \%$ of women go on to develop Non-Insulin Dependent Diabetes Mellitus (NIDDM) within the next seven years [8]. The maternal hyperglycemia causes the fetus to secrete more insulin, resulting in stimulation of fetal growth and macrosomia [1]. Offspring of women with GDM is at an increased risk of developing diabetes later in life [9]. The recognition of GDM is important because the therapy can reduce the prenatal morbidity and mortality [9].

Although GDM occurs only temporarily in pregnant women worldwide with glucose regulation returning to normal after delivery, it poses risks to the pregnancy itself, prenatal morbidity, chronic hypertension, and increased risk to woman of developing type $2 \mathrm{Di}$ abetes (T2D) formerly known as Non-Insulin Dependent Diabetes Mellitus (NIDDM) af- 
ter delivery or later in life [4]. Although many studies have been conducted on the complications and risks associated with GDM, in Rwanda, the documentation of the prevalence and risk disposal of pregnant women is not known, hence the need to carry out this study was to know the prevalence of GDM in some parts of Rwanda with the intention of carrying out the research on a wider scale to cover the whole country in the near future.

\section{Methodology}

A cross-sectional study was carried out at Kimironko, Kicukiro and Muhima Health Centres located in Kigali city, the most urbanized among the five provinces of Rwanda from March to May, 2012 in 96 pregnant women. Samples were collected using nonprobability convenient sampling strategy. The sample size of 96 pregnant women was selected, where 32 pregnant women were conveniently selected from each of the three Health Centres. The sample size was calculated by using the following formula:

$$
\begin{gathered}
n=p(100-p) / e^{2} \\
e=S / 2
\end{gathered}
$$

(Kirkwood B (1988). Essential of Medical Statistics, Oxford: Blackwell Scientific Publications).

where: $n$ : sample size;

$p$ : prevalence in \%;

e: required standard deviation error;

$S$ : Standard deviation.

In this study, the sample size was calculated as follows.

Prevalence range: $1 \%-10.5 \%$

$$
\begin{gathered}
p=5.75 \% \\
s=4.75 \text { and } e=2.375 \\
n=5.75(100-5.75) /(2.375)^{2}
\end{gathered}
$$

$n=96$; therefore, sample size is 96 pregnant women.

The gestation period of pregnant women was recognized through record of prenatal care service in order to know which trimester they were. Data was collected using laboratory diagnostic tests (Glucose Oxidase method), questionnaires and data capture sheet. The Questionnaire helped us to capture the following information: age, weight, family history of diabetes and fasting status. Data capture sheet was used to record the glucose concentration and observations about the results found in order to classify as either having GDM or not. Fasting capillary blood samples were collected from pregnant women who were selected as participants from the studied areas. Participants had their blood samples tested for glucose using an ACCU-CHECK-Aviva Plus glucometer which applies glucose oxidase method principle. Data was analyzed in terms of percentages and frequencies. The tables were done using Microsoft office word and Microsoft office excel. In addition, Confidence Interval (95\%) was calculated as mean \pm 2 SD using SPSS version 20 . 


\section{Inclusion Criteria}

All pregnant women who visited the studied health facilities during the study period aged between $21-45$, who were between $24^{\text {th }}$ and $28^{\text {th }}$ week of gestation, who had not developed any type of diabetes before pregnancy and who fasted between $8-12$ hours; were included in this project.

\section{Exclusion Criteria}

Pregnant women aged below 21 and above 45 years who were in first or third trimester of pregnancy; who had previously developed any type of diabetes before pregnancy and those in the second trimester but had not fasted for $8-12$ hours overnight were excluded from the study.

\section{Ethical Consideration}

This study was conducted after obtaining an informed consent from the ethical committee of Kigali Health Institute administration and written permission letter from the three Health Centers. Participants were informed about the aim of the study and participated voluntarily and actively in the study and were allowed to withdraw at any point during the study. Clear instructions were given to participants and they were assured about confidentiality of the research findings. Results were communicated to the responsible health workers at the Health Centers under study.

\section{Results}

During the study period, fasting blood glucose analysis was performed on 96 pregnant women from March to May 2012 with a prevalence of 8.3\%, mean age $27 \pm 9.8$ (95\% CI). Table 1 shows that out of 96 pregnant women, who participated in the study, $23 \%$ were hypoglycemic, $68.7 \%$ had normal blood glucose levels and $8.3 \%$ were found to have GDM. A high prevalence of GDM 5 out of 96 (5.2\%), was found in pregnant women aged between 26 - 30, 2 out 96 (2.1\%) of pregnant women were in 21 - 25 age group, 1 out of $96(1 \%)$ of pregnant woman were in 31 - 35 age group and there were no cases of GDM in pregnant women in the $36-40$ and $41-45$ age groups. (Table 2)

Table 1. Prevalence of GDM in pregnant women according to age.

\begin{tabular}{|c|c|c|c|c|c|}
\hline \multirow[t]{2}{*}{ Age group } & \multirow{2}{*}{$\begin{array}{l}\text { Low: }<76 \mathrm{mg} / \mathrm{dl} \\
(<4.2 \mathrm{mmol} / \mathrm{l})\end{array}$} & \multirow{2}{*}{$\begin{array}{c}\text { Normal: } \\
76-110 \mathrm{mg} / \mathrm{dl} \\
(4.2-6.1 \mathrm{mmol} / \mathrm{l})\end{array}$} & \multicolumn{2}{|c|}{$\begin{array}{l}\text { High/GDM: }>110 \mathrm{mg} / \mathrm{dl} \\
(>6.1 \mathrm{mmol} / \mathrm{l})\end{array}$} & \multirow[t]{2}{*}{ Total } \\
\hline & & & Number & Percentage (\%) & \\
\hline $21-25$ & 9 & 32 & 2 & 2.1 & 43 \\
\hline $26-30$ & 6 & 20 & 5 & 5.2 & 31 \\
\hline $31-35$ & 5 & 8 & 1 & 1 & 14 \\
\hline $36-40$ & 2 & 5 & 0 & 0 & 7 \\
\hline $41-45$ & 0 & 1 & 0 & 0 & 1 \\
\hline Total frequency & 22 & 66 & & 8 & 96 \\
\hline $\begin{array}{c}\text { Total } \\
\text { percentage }(\%)\end{array}$ & 23 & 68.7 & & 8.3 & $100 \%$ \\
\hline
\end{tabular}


Table 2. Frequency of risk factors associated with GDM.

\begin{tabular}{cccc}
\hline SN & Types of risk factors & Number of Pregnant women & Proportion of GDM \\
\hline 1 & Age group of 26 - 30 years (most prevalent) & 32 & 5 \\
2 & Family history of diabetes & 5 & 1 \\
3 & Obesity & 4 & 0 \\
\hline
\end{tabular}

This table shows that among pregnant women that were found to have GDM in this study, five (5.2\%) were in the 26 - 30 age group whereas the other age groups contributed to $3.1 \%$ of the total GDM proportion. Table 2 also shows that one pregnant woman with family history of diabetes developed GDM whereas obesity did not reveal any association with GDM.

\section{Discussion}

The findings from this study were analyzed according to standards and compared with other studies. Some previous studies that were done used glucometer whereas others applied calorimetric assays for measuring blood glucose. The time of screening was generally between the 24th and 28th week of gestation. The difference in prevalence with other studies maybe due to differences in the screening methods, diagnostic criteria used or population studied [5].

The prevalence of GDM in this study was $8.3 \%$ and there were no previous studies done in Rwanda to compare with. This would have helped us for monitoring the status and progress of GDM according to decades or centuries. The prevalence of GDM has been reported variably from $1 \%$ to $14 \%$ worldwide depending on the population studied and the diagnostic tests employed [4]. In the study done by Ahia et al., 2008, in Tehran to evaluate the prevalence of GDM and its risk factors for the whole cohort study was reported to be $6.8 \%$ [11], compared to our study which revealed that $8.3 \%$ of pregnant women developed GDM.

A study that was carried out in northern Ethiopia by Berhane et al., 1999, to determine the prevalence of gestational diabetes mellitus in rural pregnant mothers found that the prevalence of GDM was 3.7\% [12]. This prevalence was low compared to this study. A study done by Mamabolo et al., 2007, to examine the prevalence of gestational diabetes mellitus and the effect of weight on measures of insulin secretion and insulin resistance in third-trimester of pregnant women residing in the central region of Limpopo Province, South Africa, found that the prevalence of GDM was 8.8\% [13]. Women with GDM were significantly older and had more children compared with women with a normal response to the Oral Glucose Tolerance Test (OGTT). However, the age and number of children leading to risk of developing GDM was not elucidated. Nevertheless, the age was in agreement with our findings where the peak of GDM was found in age group of 25 - 30 contributing to $5 \%$ of the total GDM \%. In this study we did not investigate the number of children per pregnant woman who participated in the study, but authors are convinced that it might be a contributing factor to GDM. In the study 
done by Ahia et al., 2008, it was reported that family history of diabetes has a strong correlation with occurrence of GDM where the prevalence was $53(2.8 \%)$ whereas in our study only one pregnant woman (1.04\%) developed this condition. This variability might be due to the heritability or other diversities that need to be pin pointed out as the era of this research field progresses.

According to the study done by Bener A, Saleh NM, Al-Hamaq A. (2011), the prevalence of GDM in Qatar was 16.3\% and women with GDM were significantly higher in the age group of 35 - 45 years. Advanced maternal age, low monthly income, family history of diabetes, and obesity were the main significant risk factors for GDM in their study [6]. This is contrary to our findings where the most affected age group was 26 30 years. In our findings, the obesity has not revealed any risk factor for GDM, the monthly income was not accounted in our study, but authors are also keen on finding out the conveying reasons behind the economic status and GDM. In the study done by Fatema Jawad and Parvin Kanji Irshaduddin (1996), in Pakistan, the most affected age group by gestational diabetes mellitus was in the range of 25.1 and 30 years of age with prevalence of $49.48 \%$ for GDM [14] \& [15]. This is in agreement with findings of our study, where the most affected age group was in the range of 26 to 30 years. A study done in Nigeria; the prevalence of GDM was $2.98 \%$ per 1000 pregnancies. Maternal age and gestational age at diagnosis (mean $\pm \mathrm{SD}$ ) were $31.0 \pm 2.4$ years and $23.88 \pm 8.2$ weeks respectively [16]. This prevalence is lower than that of this study and they did not assess family history or other associated risk factors to GDM.

\section{Conclusion and Future Directions}

To sum up, the findings of this study point out that the prevalence of GDM was $8.3 \%$ in the studied areas with the most affected age group of 26 - 30 years. Family history of diabetes and age were found to be risk factors of GDM. The authors recommend that further researches be carried out using a large sample size across Rwanda on the prevalence of GDM, its associated risk factors other than those assessed, but also hormones produced during pregnancy, fats deposits, number of children and monthly income per pregnant woman. The authors also strongly suggest the use of oral glucose tolerance test for further researches to be carried out on the same field of study. All in all, authors proffer other researchers to ponder and decipher molecular mechanisms of GDM using animal model (for both insulin sensitive and insulin resistant) as a cutting-edge in regard to effective diagnosis, prediction and design of novel treatment, as well as prevention of GDM. More than that, a follow up on hypoglycemic pregnant women can serve as an overarching insight towards improvement of research by unraveling reasons behind that condition which in reverse leads to welfare of the concerns.

\section{Limitations of the Study}

It was not successful to progress towards further testing of GDM by using Oral Glucose Tolerance Test because of budget constraints as it takes longtime to perform. Moreover, it also requires that participants must be inpatients. 


\section{Acknowledgements}

The authors are grateful to Almighty God. They are also obliged to the government of Rwanda through the ministry of education for sponsoring this research project. Incredible appreciations go to Herbert Mapira and Aliyu Attahiru for their support towards implementation and completion of this study. The authors also pay sincere thanks to In charge of Kicukiro, Kimironko and Muhima health centres for their invaluable collaboration and authorization to carry the research in their respective health facilities.

\section{References}

[1] Christenson, R.H., Gregor, L.C. and Johnson, L.J. (2001) Appleton \& Lange's Outline Review. Clinical Chemistry, McGraw-Hill Companies, New York, Chicago, Lisbon, Madrid, 16.

[2] Carr, D.B. and Gabbe, S. (1998) Gestational Diabetes: Detection, Management, and Implications. Clinical Diabetes, 16, 4.

[3] Burtis, C.A. and Ashwood, E.R. (1999) Clinical Chemistry. 3rd Edition, W.B. Saunders Company, Philadelphia, 1815.

[4] Sue Kirkman, M. and Schaffner, W. (2012) Gestational Diabetes Mellitus: ADA. Diabetes Care, 35, 941-942. http://dx.doi.org/10.2337/dc12-0164

[5] Moore, T.R., et al. (2005) Diabetes Mellitus and Pregnancy. Med/2349 at eMedicine.

[6] Bener, A., Saleh, N.M. and Al-Hamaq, A. (2011) Prevalence of Gestational Diabetes and Associated Maternal and Neonatal Complications in a Fast-Developing Community: Global Comparisons. International Journal Women's Health, 3, 367-373. http://dx.doi.org/10.2147/IJWH.S26094

[7] Setji, T.L., Brown, A.J. and Feinglos, M.N. (2005) Gestational Diabetes Mellitus. Clinical Diabetes, 30, 17-24. http://dx.doi.org/10.2337/diaclin.23.1.17

[8] Smith, A.F., Beckett, G.J., Walker, S.W. and Rae, P.W.H. (1998) Clinical Biochemistry. 6th Edition, Blackwell Science Ltd., United Kingdom, 156.

[9] Anderson, S.C. and Cockayne, S. (2003) Clinical Chemistry: Concepts and Applications. McGraw-Hill Companies, USA, London, New Delhi, 634.

[10] Burtis, C.A. and Ashwood, E.R. (2001) Fundamental of Clinical Chemistry. 5th Edition, W.B. Saunders Company, Philadelphia, London, St Louis, Sydney, Toronto , 1815

[11] Garshasbi, A., Faghihzadeh, S., Naghizadeh, M.M. and Ghavam, M. (2008) Prevalence and Risk Factors for Gestational Diabetes Mellitus in Tehran. Journal of Family and Reproductive Health, 2, 75-80.

[12] Seyoun, B., et al. (1999) Prevalence of Gestational Diabetes Mellitus in Rural Pregnant Mothers in Northern Ethiopia. Journal of Diabetes Research and Clinical Practice, 46, 247251.

[13] Mamabolo, R.L., Alberts, M., et al. (2007) Prevalence of Gestational Diabetes Mellitus and the Effect of Weight on Measures of Insulin Secretion and Insulin Resistance in ThirdTrimester Pregnant Rural Women Residing in the Central Region of Limpopo Province, South Africa. Diabetic Medicine, 24, 233-239. http://dx.doi.org/10.1111/j.1464-5491.2006.02073.x

[14] Schmidt, M.I., Matos, M.C., Reichelt, A.J., Forti, A.C., de Lima, L. and Duncan, B.B., Brazilian Gestational Diabetes Study Group (2000) Prevalence of Gestational Diabetes Mellitus: 
Do the New WHO Criteria Make a Difference? Diabetic Medicine, 17, 376-380.

http://dx.doi.org/10.1046/j.1464-5491.2000.00257.x

[15] Jawad, F. and Irshaduddin, P.K. (1996) Prevalence of Gestational Diabetes and Pregnancy Outcome in Pakistan. Eastern Mediterranean Health Journal, 2, 268-273.

[16] Wokoma, F.S., Celestine, T.J. and Enyindah, C.E. (2001) Gestational Diabetes Mellitus in a Nigerian Antenatal Population. Tropical Journal of Obstetrics and Gynaecology, 18, 56-60. http://dx.doi.org/10.4314/tjog.v18i2.14430

Submit or recommend next manuscript to SCIRP and we will provide best service for you:

Accepting pre-submission inquiries through Email, Facebook, LinkedIn, Twitter, etc. A wide selection of journals (inclusive of 9 subjects, more than 200 journals)

Providing 24-hour high-quality service

User-friendly online submission system

Fair and swift peer-review system

Efficient typesetting and proofreading procedure

Display of the result of downloads and visits, as well as the number of cited articles Maximum dissemination of your research work

Submit your manuscript at: http://papersubmission.scirp.org/

Or contact jdm@scirp.org 